\title{
MORFOLOGI CERITA RAKYAT MAK YONG DAERAH KAMPUNG MATANG ARANG, KECAMATAN BINTAN TIMUR, KEPULAUAN RIAU
}

\author{
Riau Wati \\ Fakultas Keguruan dan Ilmu Pendidikan \\ Universitas Maritim Raja Ali Haji \\ Pos-el: riauwatimhum@yahoo.com
}

\begin{abstract}
Abstrak
Penelitian ini mengambil karya sastra seni peran Mak Yong sebagai objek penelitian dan pokok masalah yang menjadi penelitian berkaitan dengan penyebaran fungsi tokoh cerita rakyat Mak Yong, berdasarkan teori strukturalisme Vlademir Propp, karena pembahasan terhadap karya sastra lama tersebut masih tergolong sedikit dan teori Vladimir Propp belum pernah diuji dalam cerita rakyat Mak Yong oleh peneliti sebelumnya. Penelitian ini menggunakan metode pustaka, metode deskripsi dan metode struktural, karena berdasarkan metode tersebut dapat segera dikemukakan hasil penelitian, disertai pertanggungjawaban mengenai alasan pemilihan metode tersebut. Berdasarkan hasil penelitian (1) fungsi pelaku menjadi unsur yang stabil dan tetap di dalam sebuah cerita tanpa memandang bagaimana dan siapa yang melakukannya, (2) fungsi pelaku yang diketahui jumlahnya terbatas, (3) urutan fungsi pelaku di dalam cerita rakyat selalu sama dan (4) sebuah cerita rakyat memiliki kesamaan jika dipandang dari struktural. Kesimpulannya, hasil penelitian yang ditemui dalam cerita rakyat Mak Yong tidak ada perbedaan antara hasil penelitian fungsi pelaku menurut Vladimir Propp.
\end{abstract}

Kata kunci: morfologi, foklor, Mak Yong

\begin{abstract}
This research took the literary work of art of the role of Mak Yong as the research object and the subject matter of the research related to the deployment of the function figure folklore Mak Yong, based on the theory of structuralism Vlademir Propp, for a discussion of the work of old literature is still quite a bit and the theory of Vladimir Propp has not been tested in folklore Mak Yong by previous researchers. This study uses literature, method descriptions and structural methods, as based on the method can be immediately presented results of the study, along with the accountability of the reasons for the selection of the method. Based on the results of the study (1) the function of the perpetrator becomes an element that is stable and remains in a story regardless of how and who did it, (2) the function of the perpetrators are known to a limited number, (3) the order of the functions actors in folklore is always the same and (4) a folklore have in common when viewed from the structural. In conclusion, the results encountered in folklore Mak Yong is no difference between the results of research actors function according to Vladimir Propp.
\end{abstract}

Key words: morphology, folklore, and Mak Yong

\section{PENDAHULUAN}

Bangsa Indonesia sangat beruntung, karena memiliki khazanah sastra lama dalam jumlah besar, yaitu; dalam bentuk lisan mau- pun dalam bentuk tulisan. Karya sastra lama tersebut tersebar luas di beberapa daerah, umumnya dalam bahasa daerah tempat penyebarannya. Sebagai khazanah bangsa Indonesia 
yang memiliki akar yang kuat pula di Indonesia, tiap daerah menyumbangkan karya sastra lama dalam bentuk tertulis di pustaka Indonesia.

Salah satu daerah yang masih menyimpan sastra lama adalah daerah Kepri. Meskipun banyak menyimpan khazanah sastra lama, tetapi penelitian terhadapnya belum banyak, oleh karena itu penelitian sastra lama daerah Kepri perlu dilakukan. Hal ini didorong oleh kekhawatiran akan punahnya sastra lama tersebut. Selain itu sastra lama sebagai khazanah budaya bangsa mengandung makna dan fungsi tertentu bagi masyarakat pemiliknya.

Sastra lama merupakan peninggalan masa lampau yang tidak diketahui pengarangnya dan milik kolektif suatu masyarakat. Sebagai hasil karya masa lampau mampu menginformasikan mengenai berbagai segi kehidupan yang pernah ada. Karya-karya dengan kandungan informasi mengenai masa lampau itu tercipta dari latar sosial budaya masyarakat yang tidak ada lagi atau yang tidak sama dengan latar sosial budaya masyarakat pembaca masa kini. Agar karya sastra lama dapat dipahami, maka diperlukan penanganan dan pengkajian khusus dengan tujuan supaya isi yang terkandung di dalamnya dapat diketahui.

Penelitian ini mengambil karya sastra cerita rakyat Mak Yong sebagai objek penelitian. Alasan pemilihan karya sastra lama tersebut, karena pembahasan terhadap karya sastra lama tersebut masih tergolong sedikit, sehingga pemaknaan karya sastra lama tersebut belum seutuhnya.

Pokok masalah yang menjadi penelitian berkaitan dengan penyebaran fungsi tokoh cerita rakyat Mak Yong, berdasarkan teori strukturalisme Vlademir Propp. Masalah yang ingin diangkat dari penelitian ini, berkaitan dengan penyebaran fungsi pelaku, urutan fungsi pelaku, bentuk skema kerangka urutan fungsi pelaku, lingkungan tindakan fungsi pelaku, dan skema pergerakan cerita rakyat Mak Yong.

Pemilihan teori strukturalisme Vlademir Propp, karena analisis morfologi cerita rakyat pernah dilakukan oleh Vlademir Propp. Objek penelitian yang dilakukan ialah seratus cerita rakyat Rusia yang disebut fairy tales. Sebagai anggapan dasar penelitian cerita rakyat Mak Yong dipergunakan pendapat Propp (1979): 21-23): (1) fungsi watak menjadi unsur yang stabil dan tetap di dalam sebuah cerita tanpa memandang bagaimana dan siapa yang melakukannya, (2) dalam cerita rakyat fungsi yang diketahui jumlahnya terbatas, (3) urutan fungsi di dalam cerita rakyat selalu sama dan (4) sebuah cerita rakyat memiliki kesamaan jika dipandang dari struktural. Defenisi fungsi pelaku menurut Propp ialah tindak seorang tokoh yang dibatasi dari segi maknanya untuk jalan lakonnya.

Tujuan penelitian ini dapat dibagi dua, yaitu: tujuan umum dan tujuan khusus. Adapun tujuan umum, yaitu; agar cerita rakyat Mak Yong dapat dipertahankan dan jangan sampai hilang dari kehidupan masyarakat kawasan Kepulauan Riau yang merupakan satu-satunya masih tersisa di kampong Mantang Arang, Kecamatan Bintan Timur, karena cerita rakyat Mak Yong banyak mengandung nilai-nilai lama yang baik dan berguna dalam kehidupan dan tujuan khusus, yaitu; Secara teoritis untuk menganalisis fungsi pelaku cerita rakyat Mak Yong, sebagai langkah awal dalam memaknai cerita rakyat Mak Yong. Analisis fungsi merupakan salah satu unsur struktur karya sastra.

Mengingat peranan sastra Indonesia yang begitu penting, maka perlu adanya penelitian terhadap hasil sebuah karya sastra dengan maksud untuk memberikan sumbangan terhadap perkembangan apresiasi sastra Indonesia kepada masyarakat. Kegiatan penelitian dalam memahami, menikmati dan menilai hasil sebuah karya sastra tidak lain hanya untuk mencapai penciptaan sastra setinggi mungkin. Selain itu untuk menambah pengetahuan penulis dan juga menambah pengetahuan pembaca.

Penulis berharap, penelitian ini dapat menjadi sebagai bahan acuan bagi peneliti lainnya 
yang ingin menganalisis hasil sebuah karya sastra lainnya, khususnya bagi penulis yang masih muda dan sedang belajar. Adanya penelitian ini diharapkan, dapat mendorong semangat para pengarang yang masih muda dan yang sedang belajar untuk memahami dan mampu menjelaskan kelemahan-kelemahan nilai-nilai yang terkandung dalam cipta sastra yang sedang dibicarakan.

Dalam pelaksanaan penelitian ini penulis berasumsi, penelitian ini sangat bermanfaat sekali dalam mengembangkan ilmu sastra Indonesia. Penulis berkeyakinan penelitian ini belum pernah dilakukan oleh penelitian lainnya yaitu dengan judul Morfologi cerita rakyat Mak Yong daerah kampung Matang Arang, Kecamatan Bintan Timur Kepulauan Riau.

Penelitian sastra lama yang dilakukan banyak membawa hasil yang sangat bermanfaat bagi bangsa Indonesia. Hal itu bukan hanya mempunyai arti penting bagi perkembangan sastra Indonesia tetapi juga menambah wawasan serta pemahaman atas sebagian warisan budaya nenek moyang yang tertuang dalam karya sastra. Karya sastra lama memiliki nilai yang sangat tinggi di dalamnya terkandung alam pikiran, adat istiadat, kepercayaan dan sistem nilai masyarakat pada masa lampau

\section{TEORI DAN METODE}

Teori Vladimir Propp belum pernah diuji dalam cerita rakyat Mak Yong oleh peneliti sebelumnya. Namun penulis berkeyakinan, penelitian ini dapat dilaksanakan, karena sastra daerah Indonesia bisa didekati dengan teori sastra barat, sebab unsur-unsur yang ada banyak menunjuk hal-hal yang sifatnya universal.

Penelitian yang menggunakan penerapan teori Vladimir Propp sudah pernah dilakukan oleh peneliti sebelumnya, misalnya penelitian Hikayat Hang Tuah Analisis Struktur dan Fungsi oleh Prof. DR. Sulastin Sutrisno (thesis) sudah dipublikasikan dalam bentuk buku tahun 1983, penelitian Cerita Rakyat Damar Wulan
Analisis Fungsi Pelaku dan Penyebarannya Menurut Teori Vladimir Propp oleh Tirto Suwondo (thesis) sudah dipublikasikan dalam bentuk jurnal tahun 1997. Cerita rakyat Mak Yong pernah diteliti oleh mahasiswa UMRAH, hasil penelitian ditulis dalam bentuk skripsi. dan sudah dipublikasi dalam jurnal PBSI berjudul kajian semiotika naskah teater Mak Yong tahun 2015.

Salah satu kekuatan karya tulis ialah terletak pada penguasaan metode, karena berdasarkan metode tersebut dapat segera dikemukakan hasil penelitian, disertai pertanggungjawaban mengenai alasan pemilihan metode tersebut.

Penelitian ini menggunakan metode pustaka, metode deskripsi dan metode struktural. Alasan pemilihan metode pustaka, karena objek penelitian adalah pustaka cerita rakyat Mak Yong, tidak diambil dari seni pertunjukan, alasan menggunakan metode deskripsi, karena pembahasan hasil penelitian ini dideskripsi lebih lengkap, dan alasan menggunakan metode struktural, karena permasalahan pernelitian ini adalah fungsi pelaku cerita rakyat Mak Yong. Penelitian

Langkah-langkah yang ditempuh ialah sebagai berikut: Langkah awal ialah studi pustaka dan studi katalog untuk mencari dan mengumpulkan data yang berkaitan erat dengan penelitian.Langkah kedua ialah data dianalisis, dan Langkah ketiga ialah meneliti cerita seni pertunjukan rakyat Mak Yong dengan metode struktural teori Vladimir Propp seperti tertera dalam bukunya berjudul Morfology of the Folktale yang terbit pada tahun 1979. Analisis struktural cerita dilakukan dengan menempuh dua kegiatan, yaitu; menggambarkan satuan-satuan dan kedua memperhatikan dan menerangkan hubungan yang ada antara satuan-satuan.

\section{HASIL DAN PEMBAHASAN}

Berhadapan dengan suatu cerita, maka berhadapan dengan dunia kata-kata. Kata-kata 
itu menjadi petunjuk bagi pembaca mengenai maksud dan tujuan penulisan cerita. Penggunaan kata-kata dalam suatu teks merupakan unsur utama pembangun cerita, berfungsi menjelaskan tema pokok dengan menonjolkan arti dan peranan tokoh dalam cerita. Penafsiran makna judul semakin jelas, jika tema pokok yang jelas dicantumkan sebelum cerita dimulai.

Setiap unsur yang terkandung dalam struktur karya sastra memiliki peranan penting dalam proses pemberian makna. Setiap unsur tersebut saling berhubungan dan merupakan suatu kesatuan. Konsep hubungan dalam karya sastra dapat dibagi dua kerangka, yaitu; 1. makna suatu unsur dalam sebuah karya sastra hanya dapat dilihat dalam hubungan dengan unsur-unsur lainnya dan 2. setiap unsur dalam sebuah karya sastra saling berhubungan dan membentuk jaringan hubungan tanpa ada yang dapat terlepas dari unsur tersebut.

Salah satu unsur yang menjadi penelitian ini adalah fungsi-fungsi pelaku dalam cerita rakyat Mak Yong. Yang disajikan dalam penelitian ini ialah definisi fungsi pelaku yang diikuti dengan lambang dan kutipan isi cerita. Kutipan isi cerita disajikan dengan maksud sebagai penjelas fungsi pelaku. Adapun hasil penelitian fungsi-fungsi pelaku dalam cerita rakyat Mak Yong tampak sebagai berikut:

\section{Struktur Cerita Raja Mahniaya}

\section{Situasi Awal (Lambang: x)}

Dalam cerita Raja Mahniaya, pengarang tidak langsung menampilkan fungsi pelaku tetapi dimulai dengan situasi awal. Masalah ini dirumuskan dalam teori Vladimir Propp yang mengatakan, sebuah cerita rakyat selalu dimulai dengan situasi awal. Situasi awal yang dimaksud ialah pertama kali menampilkan deskripsi cerita, misalnya; pengenalan namanama tokoh dan keluarga tokoh-tokoh yang nantinya akan terlibat ke dalam konflik, juga menunjukan pangkatnya. Menurut Propp, situasi awal ini bukanlah merupakan satu fungsi. Walaupun demikian, menurut Propp, situasi awal ini ialah unsur morfologi yang amat penting. Situasi awal ini diberi lambang (x).

Situasi awal cerita Raja Mahniaya ialah deskripsi singkat yang dituangkan dalam bentuk cerita. Pengarang mendeskripsikan kehidupan kerajaan Bintan yang diperintah oleh seorang raja bernama Raja Mahniaya bersama Tuan Putri. Raja mempunyai seorang putra bernama Pangeran Indra. Diceritakan tabiat putra raja, yakni suka membuat onar baik dengan anak-anak bangsawan istana maupun rakyat jelata di sekitar negeri Bintan, suka berburu binatang tidak hanya kijang, pelanduk tetapi juga lembu maupun kambing rakyat, selain itu senang menganiaya harta benda rakyat.

Kemudian muncul fungsi-fungsi berikut:

\section{Absentation 'ketiadaan' (Lambang: b)}

Fungsi kesatu yang ditampilkan pengarang dalam cerita Raja Mahniaya menceritakan, seorang Tuan Putri yang ingin berliburan ke Gunung Bintan. Kepergian Tuan Putri ditemani dengan seorang pengawal baginda putri bernama Awang Peran. Kalau mengikuti klasifikasi Propp, fungsi ini termasuk dalam kelompok seorang anggota keluarga meninggalkan rumah (Definisi: ketiadaan. Lambang: b).

\section{Villainy 'kejahatan' (Lambang: A)}

Fungsi kedua yang ditampilkan pengarang dalam cerita Raja Mahniaya menceritakan, sebelum Tuan Putri beserta rombongan sampai ke Gunung Bintan, tanpa sepengetahuan Tuan Putri, para gembala mendekati Awang Peran dan mengadukan perilaku putra mahkota sekarang yang sedang memusnahkan kebun rakyat yang terletak di ujung desa. Mendengar kondisi seperti itu, akhirnya Awang Peran mencari akal, agar Tuan Putri tidak melanjutkan ke Gunung Bintan. Kalau mengikuti klasifikasi fungsi ini termasuk dalam kelompok penjahat menyebabkan kesusahan atau kecederaan kepada seorang anggota keluarga (Definisi: kejahatan. Lambang: A). 


\section{Mediation, The Connective Incident 'per- antaraan' (Lambang: B)}

Fungsi ketiga yang ditampilkan pengarang dalam cerita Raja Mahniaya menceritakan, agar permasalahan rakyat jelata dapat diatasi, Awang Peran mulai mencari jalan keluarnya dengan meminta pertolongan kepada inang dan dayang. Ketika Awang Peran berhasil melakukan tipu muslihatnya terhadap Tuan Putri dengan perlahan Awang Peran menyampaikan semua permasalah yang sedang dihadapi rakyat jelata kepada Tuan Putri. Tuan putri mulai memahaminya dan akhirnya Awang Peran diminta untuk membantu memecahkan permasalahan tersebut. Kalau mengikuti klasifikasi fungsi ini termasuk dalam kelompok seorang anggota keluarga memerlukan sesuatu atau berkeinginan untuk mendapatkan sesuatu (definisi: perantaraan. lambang: B).

\section{Struggle 'bertempur' (Lambang: $\mathrm{H}$ )}

Fungsi keempat yang ditampilkan pengarang dalam cerita Raja Mahniaya menceritakan, Ketika Pangeran Indra dan para pembatok mulai lagi merusak sekalian tanaman serta membunuh binatang peliharaan rakyat Ulu Bintan seperti dulu-dulu juga, maka Awang Peran segera menemui pangeran. Pangeran Indra dan para pembatok sangat marah sekali kepada Awang Peran, karena dianggap lancang mulut, mengadu kepada Raja Mahniaya. Akhirnya Awang Peran diserang oleh para pembatok dan rombongan Pangeran Indra, sehingga terjadi pertarungan antara Awang Peran dengan rombongan Pangeran Indra dan pembatok. Kalau mengikuti klasifikasi fungsi ini termasuk dalam kelompok pahlawan dan penjahat terlibat di dalam pertempuran (Definisi: bertempur. Lambang: $\mathrm{H}$ ).

\section{Victory 'kemenangan' (Lambang: I)}

Fungsi kelima yang ditampilkan pengarang dalam cerita Raja Mahniaya menceritakan, pertarungan sengit yang terjadi antara Awang Peran dengan rombongan Pangeran Indra dan para pembatok menjadikan rombongan Pange- ran Indra dan para pembatok menjadi kalah. Pertarungan tersebut dimenangkan oleh Awang Peran. Awang Peran menjelaskan kepada kepada Tuan Putri, Pangeran Indra sudah terpengaruh oleh pembatok lanun. Semua terjadi, karena kesalahan Paduka Raja Mahniaya sendiri. Kalau mengikuti klasifikasi fungsi ini termasuk dalam kelompok penjahat dikalahkan (Definisi: kemenangan. Lambang: I).

\section{Recognition 'pahlawan dikenali' (Lam- bang: Q)}

Fungsi keenam yang ditampilkan pengarang dalam cerita Raja Mahniaya menceritakan, Raja Mahniaya mulai memahami, ternyata Awang Peran sudah berbuat benar. Baginda Raja Mahniaya mulai sadar dan insaf atas perbuatannya yang selalu mempercayai perbuatan anaknya dan tidak pernah percaya dengan pengaduan rakyat jelata. Baginda Raja mulai membenarkan tindakan terpuji Awang Peran. Kalau mengikuti klasifikasi fungsi ini termasuk dalam kelompok pahlawan dikenali (Definisi: pahlawan dikenali. Lambang: Q).

\section{Wedding 'perkawinan' (Lambang: W)}

Fungsi ketujuh yang ditampilkan pengarang dalam cerita Raja Mahniaya menceritakan, setelah masalah dapat diselesaikan dan Awang Peran dikenali, sebagai ucapan terimakasih, maka Raja Mahniaya menjodohkan Tuan Putri dengan Awang Peran. Perkawinan itu dimeriahkan sebesar-besarnya pertanda, antara pihak kerajaan dan rakyat jelata yang selama ini berpecah belah, kini menjadi bersatu. Kalau mengikuti klasifikasi fungsi ini termasuk dalam kelompok pahlawan berkawin dan menaiki tahta (Definisi: perkawinan. Lambang: W).

Demikian berakhirnya cerita Raja Mahniaya dengan happy ending. Situasi akhir ini oleh Propp diberi lambang $(X)$

\section{Struktur cerita Putra Lokan}

\section{Situasi Awal Lambang: $x$ )}

Dalam cerita Putra Lokan, pengarang tidak langsung menampilkan fungsi pelaku, tetapi 
dimulai dengan situasi awal. Masalah ini dirumuskan dalam teori Vladimir Propp yang mengatakan, sebuah cerita rakyat selalu dimulai dengan situasi awal. Situasi awal yang dimaksud ialah pertama kali menampilkan deskripsi cerita, misalnya; pengenalan nama-nama tokoh dan keluarga tokoh-tokoh yang nantinya akan terlibat ke dalam konflik, juga menunjukan pangkatnya. Menurut Propp, situasi awal ini bukanlah merupakan satu fungsi. Walaupun demukian, menurut Propp, situasi awal ini ialah unsur morfologi yang amat penting. Situasi awal ini diberi lambang $(\mathrm{x})$.

Situasi awal cerita Putra Lokan ialah deskripsi singkat yang dituangkan dalam bentuk cerita. Pengarang mendeskripsikan sebuah kerajaan yang terletak di Hulu Sungai Bintan diperintah oleh seorang raja bersama permaisurinya. Keadaan raja dan permaisuri selalu bersedih hati, karena sepuluh tahun menikah belum mempunyai putra. Raja dan permaisuri sering dihibur oleh pengasuhnya bernama Awang Peran, sehingga muncul fungsi-fungsi berikut:

\section{Absentation 'ketiadaan' (Lambang: b)}

Fungsi kesatu yang ditampilkan pengarang dalam cerita Putra Lokan menceritakan, usaha raja dan permaisuri untuk mendapatkan putra sudah banyak dilakukan. Raja dan permaisuri sangat mempercayai Awang Peran. Akhirnya raja dan permaisuri keluar istana untuk hilir mudik sungai memberi sedekah kepada fakir miskin. Awang Peran diajak raja dan permaisuri untuk ikut hilir mudik sungai. Kalau mengikuti klasifikasi Propp, fungsi ini termasuk dalam kelompok seorang anggota keluarga meninggalkan rumah (Definisi: ketiadaan. Lambang: b).

\section{Lack 'kekurangan' (Lambang: a)}

Fungsi kedua yang ditampilkan pengarang dalam cerita Putra Lokan menceritakan, raja dan permaisuri sangat berharap sekali, semoga usaha yang dilakukan terkabulkan, karena keinginan untuk mendapatkan putra sangat besar sekali. Diceritakan selama perjalanan hilir mudik sepanjang Sungai Bintan dari hulu hingga ke hilir, permaisuri gemar makan lokan. Melihat kondisi tersebut, raja melihat perubahan pada diri permaisuri. Ternyata permaisuri berbadan dua. Kalau mengikuti klasifikasi Propp, fungsi ini termasuk kelompok seorang anggota keluarganya memerlukan sesuatu atau berkeinginan untuk mendapatkan sesuatu (Definisi: kekurangan. Lambang: a).

\section{Mediation, The Connective Incident 'per- antaraan' (Lambang: B)}

Fungsi ketiga yang ditampilkan pengarang dalam cerita Putra Lokan menceritakan, beberapa bulan kemudian, tiba saat-saat yang ditunggu-tunggu oleh raja dan permaisuri, menyambut kelahiran putranya. Raja dan permaisuri sangat senang sekali, sehingga segala persiapan permaisuri bersalin sudah dibenahi sedemikian rupa. Belasan bidan yang ternama sudah didatangkan dari setiap penjuru negeri. Ketika kelahiraan putranya terkejutlah raja, ternyata permaisuri melahirkan seekor lokan. Raja sangat malu sekali, sehingga raja jadi murka, maka raja memerintahkan supaya permaisuri dengan putranya di buang ke hutan. Awang Peran juga diperintahkan, agar ikut bersama-sama permaisuri. Kalau mengikuti klasifikasi Propp, fungsi ini termasuk kelompok malapetaka atau kekurangan itu dinyatakan; pahlawan dihadapkan kepada suatu permintaan atau perintah (Definisi: perantaraan. Lambang: B ).

\section{Villainy 'kejahatan' (Lambang: A)}

Fungsi keempat yang ditampilkan pengarang dalam cerita Putra Lokan menceritakan, Kondisi istana Hulu Bintan yang sedang kacau. Para pembatok mulai memperebut tahta kerajaan, Para pembatak tersebut itu adalah dari ahli waris raja yang gila kedudukan dan kekuasaan. Raja Hulu Bintan dipaksa turun dari tahta kerajaan tersebut. Kalau mengikuti klasifikasi fungsi ini termasuk dalam kelompok penjahat menyebabkan kesusahan atau kecedera- 
an kepada seorang anggota keluarga (definisi: kejahatan. lambang: A).

\section{Struggle 'bertempur' (Lambang: $H$ )}

Fungsi kelima yang ditampilkan pengarang dalam cerita Putra Lokan menceritakan, setelah putra lokan dewasa, lalu lokan tersebut keluar dari kulitnya, membuat awang Peran terkejut, akhirnya Awang Peran membawa putra Lokan ke ibunya. Selanjutnya diceritakan, ketika kondisi istana Hulu bintan semakin kacau dan raja turun tahta sampai baginda dipenjara pada sebuah pulau kosong, maka Suatu hari Awang Peran, putra lokan dan permaisuri bermufakat untuk membebaskan baginda raja dan memperebut kerajaan Hulu Bintan kembali. Ketika memperebut kerajaan Hulu Bintan, terjadilah pertarungan antara Awang Peran dan para pembatok. Putra lokan ikut pula dalam pertempuran tersebut. Kalau mengikuti klasifikasi Propp, fungsi ini termasuk kelompok pahlawan dan penjahat terlibat di dalam pertempuran (Definisi: bertempur. Lambang: H).

\section{Victory 'kemenangan' (Lambang: I)}

Fungsi keenam yang ditampilkan pengarang dalam cerita Putra Lokan menceritakan, Pertarungan yang terjadi antara Awang Peran dan putra Lokan dengan para pembatok, diakhiri dengan kemenangan oleh Awang Peran dan Putra Lokan. Dalam cerita ini para pembatok dapat dikalahkan. Kerajaan Hulu Bintan dapat dikuasai oleh Awang Peran dan putra Lokan. Kalau mengikuti klasifikasi Propp, fungsi ini termasuk kelompok penjahat ditewaskan (Definisi: kemenangan. Lambang: I

\section{Recognition 'pahlawan dikenali' (Lam- bang: Q)}

Fungsi ketujuh yang ditampilkan pengarang dalam cerita Putra Lokan menceritakan, akhirnya raja istana Sungai Hulu Bintan memahami, ternyata Awang Peran telah berbuat benar. Awang Peran sudah banyak membantu dan menyelamatkan istana Hulu Sungai Bintan. Kalau mengikuti klasifikasi Propp, fungsi ini termasuk kelompok pahlawan dikenali (Definisi: pahlawan dikenali. Lambang: Q).

\section{Transfiguration 'penjelmaan' (Lambang: $\mathrm{T}$ )}

Fungsi kedelapan yang ditampilkan pengarang dalam cerita Putra Lokan menceritakan, Setelah semua masalah selesai dan raja sudah mengenali putra Lokan juga Awang Peran, kemudian raja Sungai Hulu Bintan meletakkan gelar kepada putra Lokan sebagai gelar Hulu Bintan dan Awang Peran sang pengasuh setia diberi jabatan Mangkubumi di raja. Kalau mengikuti klasifikasi Propp, fungsi ini termasuk kelompok pahlawan diberi rupa baru (Definisi: penjelmaan. Lambang: T).

Demikian berakhirnya cerita Putra Lokan dengan happy ending. Situasi akhir ini oleh Propp diberi lambang $(X)$

\section{Struktur cerita Awang Putih}

\section{Situasi awal (Lambang: $x$ )}

Dalam cerita Awang Putih, pengarang tidak langsung menampilkan fungsi pelaku, tetapi dimulai dengan situasi awal. Masalah ini dirumuskan dalam teori Vladimir Propp yang mengatakan, sebuah cerita rakyat selalu dimulai dengan situasi awal. Situasi awal yang dimaksud ialah pertama kali menampilkan deskripsi cerita, misalnya; pengenalan nama-nama tokoh dan keluarga tokoh-tokoh yang nantinya akan terlibat ke dalam konflik, juga menunjukan pangkatnya. Menurut Propp, situasi awal ini bukanlah merupakan satu fungsi. Walaupun demikian, menurut Propp, situasi awal ini ialah unsur morfologi yang amat penting. Situasi awal ini diberi lambang (x).

Situasi awal cerita Awang Putih ialah deskripsi singkat yang dituangkan dalam bentuk cerita. Pengarang mendeskripsikan di sebuah kerajaan pulau bintan berkuasalah seorang raja bersama permaisuri dengan hidup rukun dan damai. Rakyatnya sangat ramai. Walaupun demikian raja memerintah sangat adil dan bijaksana, sehingga rakyatnya aman dan sejah- 
tera. Selain itu rakyatnya sangar cerdas, membuat para pembatok sulit untuk menghasut rakyat di negeri tersebut. Para pembatok berusaha terus untuk mengganggu rakyat jelata dengan berbagai cara, sehingga muncul fungsi-fungsi berikut:

\section{Absentation 'ketiadaan' (Lambang: b)}

Fungsi kesatu yang ditampilkan pengarang dalam cerita Awang Putih menceritakan, ketika sedang melaksanakan suatu nazar di istana, seluruh rakyat dan kaum istana bersuka ria. Biasanya permaisuri keluar untuk bersenangsenang di taman berserta inang dan dayang pengasuhnya. Kalau mengikuti klasifikasi Propp, fungsi ini termasuk dalam kelompok seorang anggota keluarga meninggalkan rumah (Definisi: ketiadaan. Lambang: b).

\section{Fraud 'penipuan' (Lambang: n)}

Fungsi kedua yang ditampilkan pengarang dalam cerita Awang Putih menceritakan, Ketika permaisuri bersenang-senang di taman, permaisuri melihat sekor monyet. Begitu menariknya monyet itu, hingga sampai pulang ke mahligai pun permaisuri teringat dengan monyet tersebut. Alangkah terkejutnya permaisuri, ketika melahirkan, ternyata permaisuri melahirkan anak monyet. Raja menjadi malu. Dalam kesempatan itu, maka para pembatok untuk menghasut raja dalam usaha menguasai kekayaannya. Kalau mengikuti klasifikasi Propp, fungsi ini termasuk dalam kelompok penjahat mencoba menipu korbannya dalam usaha menguasai kekayaannya (Definisi: Penipuan. Lambang: n).

\section{Villainy 'kejahatan' (Lambang: A)}

Fungsi ketiga yang ditampilkan pengarang dalam cerita Awang Putih menceritakan, raja sangat mempercayai tipu muslihat para pembatok. Ketika mendengar hasutan para pembatok, raja menjadi sangat marah sekali, sehingga permaisuri berserta monyet yang permaisuri lahirkan disingkirkan dari keramaian istana. Akhirnya permaisuri pergi meninggalkan istana ke tengah laut lepas dan tidak tahu lagi kemana arahnya. Diceritakan pula sepeninggalan permaisuri, raja selalu menghibur diri dengan bersuka ria di istana. Raja sangat akrab dengan para pembatok. Kehidupan rakyat Bintan kurang diperhatikan dan menjadi kacau. Kalau mengikuti klasifikasi Propp, fungsi ini termasuk dalam kelompok penjahat mencederakan salah seorang anggota keluarga (Definisi: kejahatan. Lambang: A)

\section{Departure 'keberangkatan' (Lambang: I)}

Fungsi keempat yang ditampilkan pengarang dalam cerita Awang Putih menceritakan, ada di Pulau Siantan bernama Awang Peran, Ia adalah rakyat jelata yang hidupnya suka memancing. Ketika Awang Peran memancing, ada seekor monyet dan seorang permaisuri terdampar di tepi laut. Lalu monyet dan permaisuri tersebut dibawa pulang. Bertahun-tahun tinggal bersama tetapi belum mengetahui asalusul permaisuri, karena permaisuri tidak pernah menceritakannya. Suatu peristiwa permaisuri mau membuka cerita. Ketika itu putra permaisuri menjelma menjadi manusia. Atas mufakat permaisuri dan Awang Peran, maka putra permaisuri diberi nama Awang Putih. Semenjang peristiwa itu Awang Peran selalu membawa Awang Putih masuk kampung untuk berkenalan dengan rakyat dusun dan mengetahui seluk beluk kehidupan manusia dipelosok-pelosok. Kalau mengikuti klasifikasi Propp, fungsi ini termasuk dalam kelompok pahlawan meninggalkan rumah (Definisi: keberangkatan. Lambang: I).

\section{Struggle 'bertempur' (Lambang: $\mathbf{H}$ )}

Fungsi kelima yang ditampilkan pengarang dalam cerita Putra Lokan menceritakan, Awang Peran dan Awang Putih mendengar ada pedagang memasukkan barang dagangan haram di negeri Bintan. Lalu Awang Peran dan Awang Putih meminta bantuan kepada rakyat kampung untuk menghancurleburkan barang dagangan tersebut. Awang Peran dan Awang Putih juga memberitahukan kepada baginda raja di Bintan tentang kejadian tersebut tetapi 
baginda marah demikian pula para pembatok, karena dianggap sudah di rugikan. Lalu terjadilah pertempuran antara Awang Peran dan Awang Putih beserta rakyat Siantan dengan angkatan kerajaan Bintan dan para pembatok. Kalau mengikuti klasifikasi Propp, fungsi ini termasuk dalam kelompok pahlawan dan tokoh penjahat terlibat dalam pertarungan (Definisi: pertempuran. Lambang: $\mathrm{H}$ )

\section{Victory 'kemenangan' (Lambang: I)}

Fungsi keenam yang ditampilkan pengarang dalam cerita Awang Putih menceritakan, pertempuran yang terjadi antara Awang Peran dan Awang Putih beserta rakyat kampung Siantan dengan angkatan raja dan para pembatok Bintan diakhiri dengan kekalahan angkatan raja dan para pembatok Bintan. Awang Peran dan Awang Putih beserta rakyat kampung Siantang menerima kemenangan. Kalau mengikuti klasifikasi Propp, fungsi ini termasuk dalam kelompok penjahat dikalahkan (Definisi: kemenangan. Lambang I)

\section{Punishment 'penjahat dihukum' (Lambang:} U)

Fungsi ketujuh yang ditampilkan pengarang dalam cerita Putra Lokan menceritakan, setelah Awang Peran dan Awang Putih dan rakyat Siantan menang, lalu kaum pembantok yang telah menjerumuskan rakyat Bintan ke lembanh perjudian, madat dan minuman keras itu dikurung ke dalam gua, sedangkan para pembesar istana paduka raja dihadapkan ke bawah duli baginda permaisuri. Akhir cerita permaisuri dan raja bertemu kembali. Raja sangat terkejut, karena yang menakluk raja adalah baginda permaisuri yang telah raja singkirkan dari istana belasan tahun yang lalu. Lalu Awang Putih bersujud kepada ayahandanya. Kerajaan Bintan kembali semarak dan berjaya sediakalanya. Kalau mengikuti klasifikasi Propp, fungsi ini termasuk dalam kelompok penjahat dihukum (Definisi: hukuman bagi penjahat. Lambang: U).
Demikian berakhirnya cerita Awang Putih dengan happy ending. Situasi akhir ini oleh Propp diberi lambang $(X)$.

\section{Urutan Fungsi Pelaku cerita rakyat Mak Yong}

Berdasarkan hasil penelitian, cerita seni pertunjukan rakyat Mak Yong dalam cerita Raja Mahniaya, Putra Lokan dan Awang Putih terdapat persamaan dalam urutan fungsi pelaku. Walaupun urutan fungsi pelaku memiliki persamaan tetapi keberadaan fungsi pelaku tidak sama, yaitu; cerita Raja Mahniaya ada 7 fungsi pelaku, cerita Putra Lokan ada 8 fungsi pelaku dan cerita Awang Putih ada 7 fungsi pelaku. Fungsi-fungsi pelaku tersebut ialah sebagai berikut:

\section{Urutan Fungsi Pelaku Cerita Raja Mahniaya}

\begin{tabular}{|l|c|}
\hline \multicolumn{1}{|c|}{ Fungsi } & Lambang \\
\hline Absentation 'ketiadaan' & B \\
\hline Villainy 'kejahatan' & A \\
\hline Mediation, the connective incident 'perantaraan & B \\
\hline Struggle 'bertempur' & H \\
\hline Victory 'kemenangan' & I \\
\hline Recognition 'pahlawan dikenali' & Q \\
\hline Wedding 'perkawinan' & W \\
\hline
\end{tabular}

\section{Urutan Fungsi Pelaku Cerita Putra Lokan}

\begin{tabular}{|l|c|}
\hline \multicolumn{1}{|c|}{ Fungsi } & Lambang \\
\hline Absentation 'ketiadaan' & $\mathrm{B}$ \\
\hline Lack 'kekurangan' & $\mathrm{A}$ \\
\hline Mediation, the connective incident 'perantaraan & $\mathrm{B}$ \\
\hline Villainy 'kejahatan' & $\mathrm{A}$ \\
\hline Struggle 'bertempur' & $\mathrm{H}$ \\
\hline Victory 'kemenangan' & $\mathrm{I}$ \\
\hline Recognition 'pahlawan dikenali' & $\mathrm{Q}$ \\
\hline Transfiguration 'penjelmaan' & $\mathrm{T}$ \\
\hline
\end{tabular}

\section{Urutan Fungsi Pelaku Cerita Awang Putih}

\begin{tabular}{|l|c|}
\hline \multicolumn{1}{|c|}{ Fungsi } & Lambang \\
\hline Absentation 'ketiadaan' & $\mathrm{B}$ \\
\hline Fraud 'penipuan & $\mathrm{n}$ \\
\hline Villainy 'kejahatan' & $\mathrm{A}$ \\
\hline Departure 'keberangkatan' & $\mathrm{I}$ \\
\hline Struggle 'bertempur' & $\mathrm{H}$ \\
\hline Victory 'kemenangan' & $\mathrm{I}$ \\
\hline Punishment 'hukuman bagi penjahat' & $\mathrm{U}$ \\
\hline
\end{tabular}

\section{Bentuk Skema Kerangka Urutan Fungsi Pe- laku cerita rakyat Mak Yong}

Berdasarkan hasil penelitian, cerita rakyat Mak Yong dalam cerita Raja Mahniaya, Putra Lokan dan Awang Putih terdapat persamaan bentuk skema kerangka urutan fungsi pelaku. Walaupun terdapat persamaan bentuk skema kerangka urutan fungsi pelaku tetapi keber- 
adaan fungsi pelaku di setiap cerita tidak seharusnya sama. Perhatikan bentuk skema urutan fungsi pelaku cerita Raja Mahniaya, Putra Lokan, dan Awang putih di bawah ini:

\section{Lingkungan Tindakan Fungsi Pelaku cerita rakyat Mak Yong}

Lingkungan Tindakan Fungsi Pelaku Cerita Raja Mahniaya:

1. Villain 'lingkungan tindakan penjahat', bagian-bagiannya: A $\mathbf{H}$

2. Hero 'lingkungan aksi pahlawan', bagian-bagiannya: H I Q W

3. Dispatcher 'lingkungan aksi perantara', bagian-bagiannya: B

4. The princess and her father 'lingkungan aksi seorang putri dan ayahnya', bagian-bagiannya: b

Lingkungan Tindakan Fungsi Pelaku Cerita Putra Lokan

1. Villain 'lingkungan tindakan penjahat' bagian-bagiannya: $\mathbf{A} \mathbf{H}$

2. Hero 'lingkungan aksi pahlawan' bagian-bagiannya: H I Q T

3. Dispatcher 'lingkungan aksi perantara', bagian-bagiannya: B

4. 'lingkungan aksi raja dan permaisuri' bagian-bagiannya: $b$ a

Lingkungan Tindakan Fungsi Pelaku Cerita Awang Putih

1. Villain 'lingkungan tindakan penjahat' bagian-bagiannya: n A H U

2. Hero 'lingkungan aksi pahlawan' bagian-bagiannya: I H I

3. 'lingkungan aksi raja dan permaisuri' bagian-bagiannya: $\mathbf{b}$

Skema Pergerakan Cerita Raja Mahniaya

1. $b$ A I W

2. $A_{------I}$

Skema Pergerakan Cerita Putra Lokan 1. b B

2. $\mathrm{A}$ $\mathrm{T}$

Skema Pergerakan Cerita Awang Putih
1. b A

2. I $\mathrm{U}$

\section{Daftar Simbol Fungsi Pelaku cerita rakyat Mak Yong}

Daftar Simbol cerita Raja Mahniaya

b Absentation 'ketiadaan' A Villainy 'kejahatan'

B Mediation 'the connective incident 'perantaraan'

H Struggle 'berjuang, bertarung'

I Victory 'kemenangan'

Q Recognition 'pahlawan dikenali'

W Wedding 'perkawinan'

Daftar Simbol cerita Putra Lokan

b Absentation 'ketiadaan'

a Lack 'kekurangan'

B Mediation 'the connective incident 'perantaraan'

A Villainy 'kejahatan'

$\mathrm{H}$ Struggle 'bertarung'

I Victory 'kemenangan'

Q Recognition 'pahlawan dikenali'

$\mathrm{T}$ Transfiguration 'penjelmaan'

Daftar Simbol cerita Awang Putih

b Absentation 'ketiadaan'

n Fraud 'penipuan'

A Villainy 'kejahatan'

I Departure 'keberangkatan'

H Struggle 'bertempur'

I Victory 'kemenangan

U Punishment 'hukuman bagi penjahat'

\section{PENUTUP}

Penelitian terhadap cerita rakyat Mak Yong dalam cerita Raja Mahniaya, Putra Lokan dan Awang Putih ditemukan (1) fungsi pelaku menjadi unsur yang stabil dan tetap di dalam sebuah cerita tanpa memandang bagaimana dan siapa yang melakukannya, (2) fungsi pelaku yang diketahui jumlahnya terbatas, (3) urutan fungsi pelaku di dalam cerita rakyat selalu sama dan (4) sebuah cerita rakyat memiliki kesamaan jika dipandang dari struktural. Hasil penelitian 
yang ditemui dalam cerita rakyat Mak Yong tidak ada perbedaan antara hasil penelitian fungsi pelaku menurut Propp.

Perlu diberi catatan, analisis cerita seni pertunjukan rakyat Mak Yong berdasarkan teori struktural berdasarkan teori Propp baru merupakan hasil uji coba teori Barat terhadap cerita rakyat Indonesia (kepri) yang hasilnya pasti masih jauh dari sempurna, oleh karena itu uji coba semacam ini perlu dilakukan terusmenerus, sehingga jika mungkin ada ditemukan ciri khusus atau keunikan tersendiri dalam cerita rakyat Nusantara (Indonesia). Kemudian penelitian sruktur cerita seni pertunjukan rakyat Mak Yong bukan tujuan akhir dari suatu penelitian melainkan perlu diadakan penelitian yang lebih lanjut, karena penelitian ini hanya mengkaji pada satu permasalahan saja yaitu berkaitan hanya dengan fungsi pelaku dalam cerita. Permasalahan yang belum dikaji dalam karangan ini, misalnya berkaitan dengan masalah alur/ jalan cerita, sudur pandang/ pusat pengisahan, perwatakan, setting/latar, gaya bahasa dan tinjauan berkaitan dengan kepengarangan, kultur budaya, kehidupan sosial, nilainilai yang terkandung dalam karya tersebut dan masih banyak lagi permasalahan yang dapat dibicarakan dalam karangan ini. Adapun tujuan yang ingin dicapai ialah untuk memaknai karya tersebut, melihat keunggulan cerita rakyat Mak Yong dan mengembangkan prinsip dan hasil penelitian Propp menjadi dasar sebuah penelitian naratif yang universal.

\section{DAFTAR PUSTAKA}

Amir, Adriyetti. 2013. Sastra Lisan Indonesia. Yogyakarta: Andi.

Eagleton, Terry. 1988. Teori Kesastraan: Satu Pengenal. Terjemahan Muhammad Haji Salleh: Dewan Bahasa dan Pustaka.

Eagleton, Tery (dalam terjemahan Salleh, $\mathrm{Hj}$, Muhammad). 1988. Teori Kesusastraan Satu Pengenalan. Kuala Lumpur. Dewan Bahasa dan Pustaka.
Junus, Umar. Karya Sebagai Sumber Makna: Pengantar Srukturalis. Kuala Lumpur: Dewan Bahasa dan Pustaka.

Junus, Umar. 1993. Dongeng tentang Cerita. Kuala Lumpur: Dewan Bahasa dan Pustaka.

Luxemburg, Van. Bal, Mieke dan Weststeijn, G, Willem (dalam terjemahan Ikram, Akhadiat). 1989. Tentang Sastra. Jakarta: Intermasa.

Muhardi. 2015. Kajian Semiotika Naskah Teater Mak Yong. UMRAH.

Propp, Vladimir. 1979. Morphology of the Folkate: Autin and Lundon;University of texas Press.

Propp, Vladimir (dalam terjemahan Taslim, Noriah). 1987. Morfologi Cerita Rakyat. Kuala Lumpur: Dewan Bahasa dan Pustaka.

Selden. Raman. 1991. Panduan Pembaca Teori Sastra Masa Terjemahan Rachmat Djoko Pradopo. Yogyakarta: Gadjah Mada University Press.

Suruto. 1991. Apresiasi Sastra Indonesia. Jakarta: Erlangga.

Syamsudin, BM. 1981. Seni Peran Mak Yong.

Jakarta: Departemen Pendidikan dan Kebudayaan.

Susanto, Dwi. 2016. Pengantar Kajian Sastra. Yogyakarta: CAPS.

Teeuw, A. 1983. Membaca dan Menilai Sastra. Jakarta: Gramedia.

Teeuw, A. 1984. Sastra dan Ilmu Sastra Pengantar Teori sastra. Jakarta: Pustaka Jaya.

Teeuw, A. 1993. Khazanah Sastra Indonesia. Jakarta: Balai Pustaka. 